\title{
Do asbestos-related pleural plaques on HRCT scans cause restrictive impairment in the absence of pulmonary fibrosis?
}

\author{
Bénédicte Clin, ${ }^{1,2}$ Christophe Paris, ${ }^{3}$ Jacques Ameille, ${ }^{4}$ Patrick Brochard, ${ }^{5}$ \\ Françoise Conso, ${ }^{6}$ Antoine Gislard, ${ }^{7}$ François Laurent, ${ }^{8,9}$ Marc Letourneux, ${ }^{2}$ \\ Amandine Luc, ${ }^{3}$ Evelyne Schorle, ${ }^{10}$ Jean-Claude Pairon ${ }^{11}$
}

${ }^{1}$ Cancers and Populations, ERI3 INSERM, Faculty of Medicine, Caen University Hospital, Caen, France

${ }^{2}$ Occupational Health Department, Caen University Hospital, Caen, France ${ }^{3}$ INSERM, Unité 954 , Faculty of Medicine, Nancy University Hospital, Nancy, France

${ }^{4}$ AP-HP, Occupational Diseases Department, Hôpital Raymond Poincaré, Garches, France ${ }^{5}$ LSTE, Occupational Diseases Department, University Hospital, Bordeaux, France

${ }^{6}$ Institut Interuniversitaire de Médecine du Travail de Paris-lle de France, Paris, France

${ }^{7}$ Occupational Diseases Department, University Hospital, Rouen, France

${ }^{8}$ Department of Thoracic Imaging, CHU Bordeaux, France ${ }^{9}$ INSERM, Unité 1046, Université Bordeaux 2, France ${ }^{10}$ ERSM Rhône-Alpes, Regional Security Insurance, Lyon, France ${ }^{11}$ INSERM, Unité 955 , Université Paris-Est Créteil, Créteil, France

\section{Correspondence to}

Dr Bénédicte Clin, Service de Santé au Travail et Pathologie Professionnelle (Occupational Health Department), CHU (University Hospital) Côte de Nacre, 14033 Caen Cedex, France; clin-b@chu-caen.fr

Received 12 March 2011 Accepted 12 June 2011 Published Online First 1 July 2011

\section{ABSTRACT}

Background It is uncertain whether isolated pleural plaques cause functional impairment

Objective To analyse the relationship between isolated pleural plaques confirmed by CT scanning and lung function in subjects with occupational exposure to asbestos.

Methods The study population consisted of 2743 subjects presenting with no parenchymal interstitial abnormalities on the high-resolution CT (HRCT) scan. Asbestos exposure was evaluated by calculation of an individual cumulative exposure index (CEI). Each subject underwent pulmonary function tests (PFTs) and HRCT scanning. Variables were adjusted for age, smoking status, body mass index, CEI to asbestos and the centres in which the pulmonary function tests were conducted.

Results All functional parameters studied were within normal limits for subjects presenting with isolated pleural plaques and for those presenting with no pleuropulmonary abnormalities. However, isolated parietal and/or diaphragmatic pleural plaques were associated with a significant decrease in total lung capacity (TLC) $198.1 \%$ predicted in subjects with pleural plaques vs $101.2 \%$ in subjects free of plaques, $p=0.0494)$, forced vital capacity (FVC) $(96.6 \%$ vs $100.4 \%, p<0.001$ ) and forced expiratory volume in $1 \mathrm{~s}$ $\left(\mathrm{FEV}_{1}\right)(97.9 \%$ vs $101.9 \%, \mathrm{p}=0.0032)$. In contrast, no significant relationship was observed between pleural plaques and $\mathrm{FEV}_{1} / \mathrm{FVC}$ ratio, forced expiratory flow at $25-75 \%$ FVC and residual volume. A significant correlation was found between the extent of pleural plaques and the reduction in FVC and TLC, whereas plaque thickness was not related to functional impairment.

Conclusions The results show a relationship between isolated parietal and/or diaphragmatic pleural plaques and a trend towards a restrictive pattern, although the observed decrease in FVC and TLC is unlikely to be of real clinical relevance for the majority of subjects in this series

\section{INTRODUCTION}

Non-malignant diseases related to asbestos exposure essentially concern the respiratory tract and include benign pleural diseases (pleural plaques, benign pleuritis, diffuse pleural fibrosis) and asbestosis (pulmonary fibrosis induced by the inhalation of asbestos fibres). ${ }^{1}$ It is well established that
Key messages

What is the key question?

- Whether isolated parietal and/or diaphragmatic pleural plaques cause functional impairment remains controversial.

What is the bottom line?

- This large-scale cross-sectional study, including information on individual cumulative exposure to asbestos and tobacco consumption, shows a relationship between isolated parietal and/or diaphragmatic pleural plaques diagnosed by CT scan and a trend towards a restrictive pattern.

\section{Why read on?}

- The strengths of the study are the large number of subjects $(n=2743)$, the individual estimation of cumulative occupational exposure to asbestos, and the accurate determination of asbestos-related pleuropulmonary abnormalities by chest CT scanning and standardised and independent double (in some cases triple) reading by expert readers of chest CT scans.

asbestosis is frequently associated with a decrease in pulmonary volume, in particular a decrease in total lung capacity (TLC) and/or a decrease in diffusion capacity. ${ }^{2}{ }^{3}$ Furthermore, several studies based on radiography have reported that diffuse pleural fibrosis can be associated with a decrease in pulmonary volume, ${ }^{4-7}$ even in the absence of asbestosis on CT scan. ${ }^{7}$ However, relationships between pleural plaques and lung function impairment still remain controversial. Several authors consider that pleural plaques have no significant effect on lung function, ${ }^{8-10}$ yet certain studies based on chest radiography have shown a decrease in pulmonary volume in subjects presenting with pleural plaques. ${ }^{11-19}$

In 2001 four FRENCH regions (Aquitaine, Upper Normandy, Lower Normandy and Rhône-Alpes) were designated by the French Ministry for Employment and Solidarity's Professional Relations Directorate and the Caisse Nationale d'Assurance Maladie des Travailleurs Salariés (CNAMTS)'s Directorate for Professional Risks ${ }^{20} 21$ to conduct a feasibility study on the medical surveillance of retired or inactive subjects who had been occupationally exposed to asbestos. This 
programme was initiated following a French consensus conference held in Paris in 1999 on medical surveillance modalities for subjects who had been occupationally exposed to asbestos. ${ }^{22}$

The aim of the present study was to analyse the relationships between isolated pleural plaques diagnosed by CT scan and lung function in a cohort of subjects occupationally exposed to asbestos, all of whom were volunteers for occupational medical surveillance.

\section{METHODS}

\section{Study population}

As previously reported, ${ }^{20} 21$ the eligible population in the selected regions consisted of retired or unemployed workers previously occupationally exposed to asbestos. Different means were used to invite people to participate in the programme including letters, trade unions and radio, television and newspaper advertisements. Volunteers who participated in the programme benefited from a free medical check-up including a CT scan of the chest and pulmonary function tests (PFTs).

The project was approved by the Cochin Hospital ethics committee in Paris and all patients received information on the study and gave their written informed consent.

\section{Asbestos exposure and tobacco consumption}

As previously described, ${ }^{20}$ evaluation of individual asbestos exposure was performed by industrial hygienists using data from a standardised questionnaire concerning all positions held throughout the individual's working career. Each job was then rated according to a 4-level scale (passive exposure: 0.01 to high exposure: 10) and a semi-quantitative index was calculated as the product of the level and the duration of exposure. The cumulative exposure index (CEI) was the sum of exposure indices calculated for each job. CEI was classified into five categories based on the distribution of values (ie, quintiles). Owing to the absence of atmospheric measurements and the lack of detailed information on exposure frequency (percentage of working time), the CEI is not expressed in $\mathrm{f} / \mathrm{ml} \times$ years but rather in 'exposure units $\times$ years'.

The subjects were classified into three categories according to tobacco consumption: smokers, ex-smokers (defined as those who had stopped smoking for at least 1 year) and non-smokers.

\section{Pulmonary function tests and body mass index}

PFTs were performed by the chest physician of the subject's choice or in hospital physiology laboratories. These PFTs included at least flow-volume curves and, in a large number of cases, a measurement of residual volume (RV) and TLC $(n=2039,74.3 \%)$. Most RV and TLC values were obtained by plethysmography. Parameters used to analyse the flow-volume curve were forced vital capacity (FVC), forced expiratory volume in $1 \mathrm{~s}\left(\mathrm{FEV}_{1}\right), \mathrm{FEV}_{1} / \mathrm{FVC}$ ratio and forced expiratory flow at $25-75 \%$ of FVC $\left(\mathrm{FEF}_{25-75}\right)$. The results were expressed as percentage of predicted values using equations published in 1993 by the European Respiratory Society, ${ }^{23}$ except for the $\mathrm{FEV}_{1} / \mathrm{FVC}$ ratio which was expressed as an absolute ratio. These equations were appropriate to the age range (37-85 years). Around 93\% of subjects included in our study were aged between 37 and 70 years, hence the choice of equations used, which covered a large fraction of our study population. Subjects with aberrant values $\left(\mathrm{FEV}_{1}>160 \%\right.$ predicted or $<10 \%$ predicted; FVC $>150 \%$ predicted or $<30 \%$ predicted) were excluded from the analysis (representing $<5 \%$ of PFTs). Body mass index (BMI) (weight $(\mathrm{kg}) /$ height $\left.\left(\mathrm{m}^{2}\right)\right)$ was calculated for each subject.

\section{HRCT scannng}

Modalities for performing CT scans were proposed by a group of experts including chest radiologists designated by the Société Française de Radiologie (French Radiology Society). Their choice was based on technical modalities likely to offer the possibility of screening all CT changes related to asbestos-induced pleural and parenchymal diseases with a limited radiation burden, in accordance with recommendations put forward by the European Directive $97 / 43$ on the health protection of individuals against the dangers of ionising radiation in relation to medical exposure. The mean dose delivered per chest CT scan was $3.6 \mathrm{mSv}$. The main parameters were set as follows: the entire chest was screened in the supine position using spiral acquisition without injection of contrast media; slice thickness $1.5-5.0 \mathrm{~mm}$; pitch 1.5-2.0, $120 \mathrm{kV}, 60-150 \mathrm{~mA}$ maximum; parenchymal images reconstructed with sharp filters and visualised with a window width around $1600 \mathrm{HU}$ and a window level of $-600 \mathrm{HU}$; soft tissue images reconstructed with smooth filters and visualised with window width around $400 \mathrm{HU}$ and window level of $50 \mathrm{HU}$. A minimum of five HRCT sections of $1 \mathrm{~mm}$ thickness performed in the prone position between the carina and the pleural recess were added.

All available CT scans underwent standardised and independent double reading (and triple reading in the case of disagreement) focused on benign asbestos-related abnormalities by a panel of seven experts in thoracic radiology.

Standardised readings were randomised, blinded to the level of asbestos exposure and smoking. A CT scan was considered as 'insufficient' when technical defects were likely to influence interpretation-for example, inappropriate slice thickness preventing correct analysis of the parenchyma, failure to produce sections in the prone position in the case of suspected interstitial abnormalities observed on images in the decubitus position, prominent motion artifacts due to insufficient apnoea.

Patients with interstitial abnormalities present on the HRCT scan were excluded from the study.

Pleural plaques were considered to be present on each hemithorax when either a single focal pleural abnormality with typical characteristics of a pleural plaque (circumscribed quadrangular pleural elevations with sharp borders and soft tissue density, possibly calcified, in typical posterolateral and anterolateral locations or in multiple bilateral less typical images with a typical location). When associated with rounded atelectasis or parenchymal bands, pleural thickenings were considered to correspond to diffuse pleural thickening (fibrosis of visceral pleura). ${ }^{24}$ The thickness was evaluated by classifying the most thickened plaque into four categories: $<2 \mathrm{~mm}, 2-5 \mathrm{~mm}$, $5-10 \mathrm{~mm}$ and $>10 \mathrm{~mm}$. The extent of pleural plaques was classified into four categories according to the cumulative area of pleural plaques detected on each section and virtually reported on the single section at the level of the carina. The following thresholds were used: $<1 \mathrm{~cm}$ length, between $1 \mathrm{~cm}$ and onequarter of the perimeter of the hemithorax, between one-quarter and one-half of the perimeter of the hemithorax, more than onehalf of the perimeter of the hemithorax.

Other abnormalities observed on the CT scan (mainly emphysema, bronchiectasis, other undifferentiated bronchial or parenchymal abnormalities) were classified as 'other abnormalities'.

\section{Statistical analysis}

Parameters described in the analysis were age, sex, BMI, smoking status, duration of exposure to asbestos, CEI, presence or absence of pleural plaques (parietal and/or diaphragmatic), 
diffuse pleural thickening and other pulmonary abnormalities. Functional parameters were compared within each group of patients with pleural abnormalities ('pleural plaques' group with two subgroups: 'isolated pleural plaques' and 'pleural plaques and other abnormalities'; and 'diffuse pleural thickening' group) and with subjects with no pleuropulmonary abnormalities ('normal CT-scan' group) using multilevel unconditional logistic models. In a second step, both global extent and thickness were included in multilevel generalised linear models in order to specifically test the effect of these two variables on each functional parameter. All models were adjusted for age, smoking status, BMI, CEI for asbestos (as independent variables) and centre as a random variable. The group with plaques only had no evidence of emphysema. The group presenting with pleural plaques associated with other abnormalities included no subjects with visceral pleural thickening, and subjects presenting with either pleural plaques and diffuse pleural thickening were classified in the 'diffuse pleural thickening' group.

Statistical analysis was performed using SAS software Version 9.2.

\section{RESULTS}

Results of PFTs and CT scans were available for 4212 subjects. After exclusion of 57 subjects with aberrant PFT values, 47 subjects with missing data on smoking status, 2 subjects with missing data on CEI, 14 subjects with missing data on BMI, 249 subjects with missing data on the centres where PFTs were conducted and 873 subjects for whom the CT scan was of insufficient quality, the population comprised 2970 subjects. Two hundred and twenty-seven patients with interstitial abnormalities were not considered for further analyses in this study, so the final study population comprised 2743 subjects (figure 1).

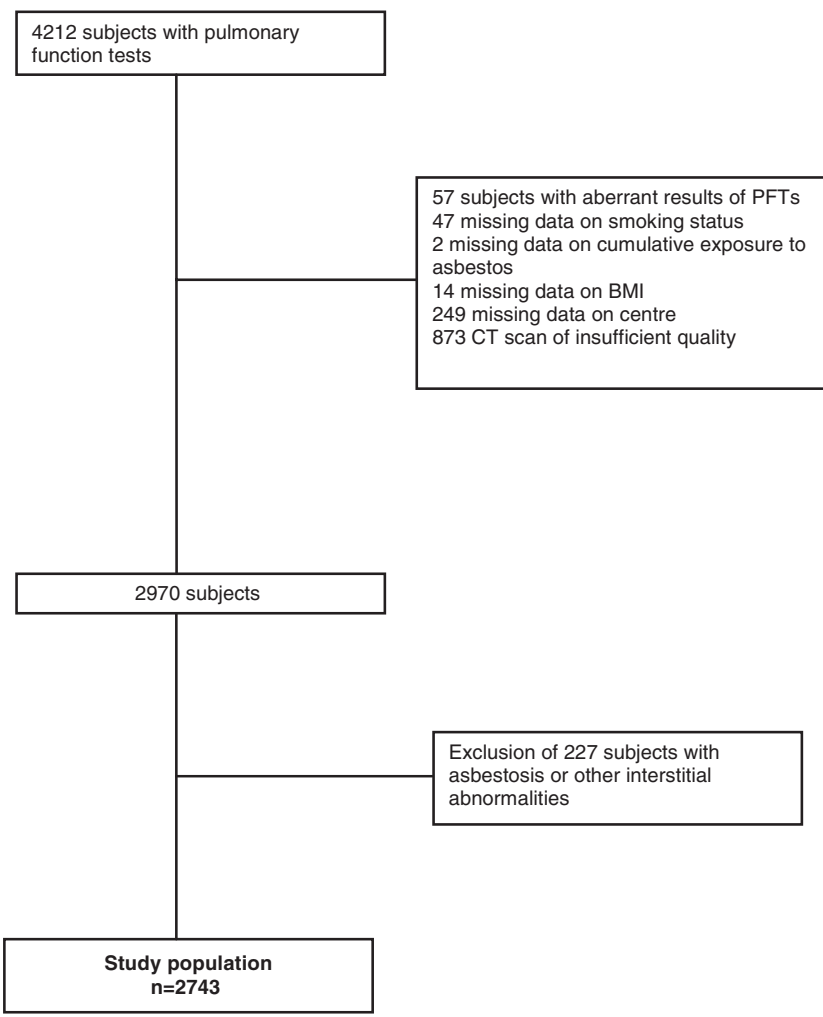

Figure 1 Study flow chart. BMI, body mass index; PFT, pulmonary function test.
The characteristics of the study population are presented in table 1 . Among the 2743 subjects in the study population, 403 $(14.7 \%)$ presented with isolated parietal and/or diaphragmatic unilateral or bilateral pleural plaques; 1802 (65.7\%) were free of pleuropulmonary abnormalities.

The distribution of parameters in the 'pleural plaques', 'diffuse pleural thickening' and 'normal CT scan' groups is shown in table 2. Multivariate analysis showed that subjects presenting with isolated pleural plaques were significantly older than those with no pleuropulmonary abnormalities, they had been exposed to asbestos for significantly longer periods $(p=0.0059)$ and had significantly higher CEI to asbestos than subjects with no pleuropulmonary abnormalities $(p<0.0001)$. There was a significantly higher proportion of non-smokers among subjects with

Table 1 Characteristics of study population $(n=2743)$

\begin{tabular}{|c|c|c|c|}
\hline Characteristics & $\mathbf{n}$ & $\%$ & Mean (SD) \\
\hline \multicolumn{4}{|l|}{ Gender } \\
\hline Male & 2618 & 95.4 & \\
\hline Female & 125 & 4.6 & \\
\hline Age (years) & & & $62.9(5.6)$ \\
\hline$<60$ & 607 & 22.1 & \\
\hline $60-74$ & 2055 & 74.9 & \\
\hline$\geq 75$ & 81 & 3.0 & \\
\hline \multicolumn{4}{|l|}{ Smoking status } \\
\hline Non-smokers & 698 & 25.4 & \\
\hline Ex-smokers & 1837 & 67.0 & \\
\hline Smokers & 208 & 7.6 & \\
\hline BMI $\left(\mathrm{kg} / \mathrm{m}^{2}\right)$ & & & $27.2(3.8)$ \\
\hline \multicolumn{4}{|l|}{ Duration of exposure to asbestos (years) } \\
\hline $1-9$ & 162 & 5.9 & $30.7(10.6)$ \\
\hline $10-19$ & 289 & 10.5 & \\
\hline $20-29$ & 541 & 19.7 & \\
\hline $30-39$ & 1173 & 42.8 & \\
\hline$\geq 40$ & 578 & 21.1 & \\
\hline \multicolumn{3}{|c|}{$\begin{array}{l}\text { Cumulative exposure index to asbestos (unit of exposure } \times \\
\text { years) }\end{array}$} & $\begin{array}{l}61.5(97.7) \\
\text { (median 25.0) }\end{array}$ \\
\hline $0-3.4$ & 631 & 23.0 & \\
\hline $3.4-17.2$ & 542 & 19.8 & \\
\hline $17.2-33.1$ & 524 & 19.1 & \\
\hline $33.1-91.9$ & 519 & 18.9 & \\
\hline$\geq 91.9$ & 527 & 19.2 & \\
\hline \multicolumn{4}{|l|}{ Pulmonary function (\% predicted) } \\
\hline FVC, mean (SD) & & & $98.8(17.5)$ \\
\hline $\mathrm{FEV}_{1}$, mean $(\mathrm{SD})$ & & & $99.6(20.2)$ \\
\hline $\mathrm{FEV}_{1} / \mathrm{FVC}$, mean (SD) & & & $104.3(11.2)$ \\
\hline $\mathrm{FEF}_{25-75}(\mathrm{n}=2708)$, mean (SD) & & & $92.4(36.2)$ \\
\hline RV ( $n=2039)$, mean (SD) & & & $109.7(34.9)$ \\
\hline TLC ( $n=2039)$, mean (SD) & & & $100.6(16.0)$ \\
\hline \multicolumn{4}{|l|}{ HRCT } \\
\hline Isolated pleural plaques & 403 & 14.7 & \\
\hline $\begin{array}{l}\text { Pleural plaques and other non-specific } \\
\text { abnormalities such as emphysema an } \\
\text { bronchiectasis (except interstitial } \\
\text { abnormalities and diffuse pleural } \\
\text { thickening) }\end{array}$ & 123 & 4.5 & \\
\hline $\begin{array}{l}\text { Diffuse pleural thickening and other } \\
\text { abnormalities such as emphysema an } \\
\text { bronchiectasis (except interstitial } \\
\text { abnormalities) }\end{array}$ & 41 & 1.5 & \\
\hline $\begin{array}{l}\text { Other pulmonary non-specific } \\
\text { abnormalities (except interstitial } \\
\text { abnormalities) }\end{array}$ & 374 & 13.6 & \\
\hline No pleuropulmonary abnormalities & 1802 & 65.7 & \\
\hline
\end{tabular}

BMI, body mass index; $\mathrm{FEF}_{25-75}$, forced expiratory flow at $25-75 \% \mathrm{FVC}$; FEV 1 , forced expiratory volume in $1 \mathrm{~s}$; FVC, forced vital capacity; RV, residual volume; TLC, total lung capacity. 
Table 2 Demographic data, asbestos exposure, and multivariate analysis of lung functional parameters according to CT scan abnormalities

\begin{tabular}{|c|c|c|c|c|c|}
\hline & $\begin{array}{l}\text { Group } 1 \\
\text { Pleural } \\
\text { plaques* }\end{array}$ & $\begin{array}{l}\text { Group 0 } \\
\text { Normal } \\
\text { CT scan } \dagger\end{array}$ & $\begin{array}{l}\text { Group } 2 \\
\text { Diffuse pleural } \\
\text { thickening } \neq\end{array}$ & $\begin{array}{l}\text { p Valueq } \\
\text { Group 1/ } \\
\text { Group } 0\end{array}$ & $\begin{array}{l}\text { p Value } \\
\text { Group 0/ } \\
\text { Group 2 }\end{array}$ \\
\hline Number of subjects & 526 & 1802 & 41 & & \\
\hline \multicolumn{4}{|l|}{ Gender } & 0.0008 & 0.12 \\
\hline Male, n (\%) & $515(97.9)$ & $1700(94.3)$ & $41(100)$ & & \\
\hline Female, $\mathrm{n}(\%)$ & $11(2.1)$ & $102(5.7)$ & - & & \\
\hline Mean (SD $\uparrow$ ) age (years) & $64.8(5.5)$ & $62.3(5.3)$ & $65.9(6.8)$ & $<0.0001$ & $<0.0001$ \\
\hline \multicolumn{4}{|l|}{ Smoking status } & $<0.0001$ & 0.25 \\
\hline Non-smokers, n (\%) & 81 (15.4) & $548(30.4)$ & $8(19.5)$ & & \\
\hline Ex-smokers, n (\%) & $403(76.6)$ & $1145(63.5)$ & $29(70.7)$ & & \\
\hline Smokers, n (\%) & $42(8.0)$ & $109(6.0)$ & $4(9.8)$ & & \\
\hline Mean (SD) BMl, $\mathrm{kg} / \mathrm{m}^{2}$ & $27.4(3.9)$ & $27.4(3.7)$ & $27.4(3.9)$ & 0.9705 & 1.00 \\
\hline \multicolumn{4}{|c|}{ Duration of exposure to asbestos (years) } & 0.0059 & 0.26 \\
\hline $1-9, \mathrm{n}(\%)$ & $23(4.4)$ & $111(6.2)$ & $2(4.9)$ & & \\
\hline $10-19, \mathrm{n}(\%)$ & $40(7.6)$ & $202(11.2)$ & $2(4.9)$ & & \\
\hline $20-29, \mathrm{n}(\%)$ & $89(16.9)$ & $365(20.3)$ & $7(17.1)$ & & \\
\hline $30-39, \mathrm{n}(\%)$ & $251(47.7)$ & $752(41.7)$ & $16(39.0)$ & & \\
\hline$\geq 40, \mathrm{n}(\%)$ & $123(23.4)$ & $372(20.6)$ & $14(34.1)$ & & \\
\hline \multicolumn{4}{|c|}{ Cumulative exposure index to asbestos (unit of exposure $\times$ years) } & $<0.0001$ & 0.14 \\
\hline $0-3.4, \mathrm{n}(\%)$ & $66(12.5)$ & $461(25.6)$ & $6(14.6)$ & & \\
\hline $3.4-17.2, n(\%)$ & $65(12.4)$ & $385(21.4)$ & $7(17.1)$ & & \\
\hline $17.2-33.1, \mathrm{n}(\%)$ & $85(16.2)$ & $365(20.3)$ & $9(21.9)$ & & \\
\hline $33.1-91.9, \mathrm{n}(\%)$ & $110(20.9)$ & $338(18.8)$ & $8(19.5)$ & & \\
\hline$\geq 91.9, \mathrm{n}(\%)$ & $200(38.0)$ & $253(14.0)$ & $11(26.8)$ & & \\
\hline Mean (SD) & $110.9(126.1)$ & $47.9(83.1)$ & $81.3(112.0)$ & & \\
\hline Median & 40.0 & 20.0 & 30.0 & & \\
\hline \multicolumn{6}{|c|}{ Pulmonary function (\% predicted $\mathrm{FVC}, \mathrm{FEV}_{1}, \mathrm{FEF}_{25-75}, \mathrm{RV}$ and TLC, absolute ratio for $\mathrm{FEV}_{1} / \mathrm{FVC}$ ) $\S$} \\
\hline FVC, mean (SD) & $96.4(17.3)$ & $100.4(16.6)$ & $87.7(20.5)$ & $<0.0001$ & $<0.0001$ \\
\hline $\mathrm{FEV}_{1}$, mean (SD) & $96.9(20.3)$ & $101.9(19.2)$ & $85.8(20.9)$ & $<0.001$ & $<0.0001$ \\
\hline $\mathrm{FEV}_{1} / \mathrm{FVC}$, mean (SD) & $78.4(9.3)$ & $80.0(7.9)$ & $76.1(7.2)$ & 0.87 & 0.04 \\
\hline $\mathrm{FEF}_{25-75}$, mean (SD) & $88.9(36.7)$ & $95.9(35.5)$ & $75.9(35.0)$ & 0.08 & 0.0019 \\
\hline $\mathrm{FEF}_{25}$, mean $(\mathrm{SD})$ & $84.3(51.9)$ & $92.4(60.5)$ & $73.8(56.2)$ & 0.06 & 0.06 \\
\hline $\mathrm{FEF}_{50}$, mean (SD) & $88.7(45.4)$ & $93.9(34.2)$ & $69.6(34.0)$ & 0.31 & $<0.0001$ \\
\hline $\mathrm{FEF}_{75}$, mean (SD) & $86.0(29.8)$ & $91.8(28.7)$ & $74.8(26.7)$ & 0.04 & 0.001 \\
\hline $\mathrm{RV}$, mean (SD) & $108.0(31.1)$ & $109.1(35.4)$ & $91.9(31.9)$ & 0.97 & 0.0056 \\
\hline TLC, mean (SD) & $98.4(14.1)$ & $101.2(16.0)$ & $88.4(16.6)$ & 0.03 & $<0.0001$ \\
\hline
\end{tabular}

*Subjects with isolated pleural plaques and subjects with pleural plaques and other abnormalities (except asbestosis and diffuse pleural thickening).

†Subjects with no CT scan abnormalities.

$\ddagger$ Subjects with diffuse pleural thickening and other abnormalities (except asbestosis).

§Adjusting for age, smoking status, BMI, cumulative exposure index (CEI) for asbestos and the centres where pulmonary function tests were conducted.

$\Phi \chi^{2}$ or Fisher tests.

$\mathrm{BMI}$, body mass index; $\mathrm{FEF}_{25-75}$, forced expiratory flow at 25-75\% FVC; FEV 1 , forced expiratory volume in $1 \mathrm{~s}$; FVC, forced vital capacity; RV, residual volume; TLC, total lung capacity.

no pleuropulmonary abnormalities $(\mathrm{p}<0.0001)$ and a higher proportion of ex-smokers among subjects presenting with isolated pleural plaques. In multivariate analysis, for both sexes, after adjusting for age, smoking status, BMI, CEI for asbestos and centre as a random variable, pleural plaques were associated with a significant decrease in TLC, FVC and $\mathrm{FEV}_{1}$. In contrast, no significant relationship was observed between pleural plaques and impairment of $\mathrm{FEV}_{1} / \mathrm{FVC}$ ratio, $\mathrm{FEF}_{25-75}$ and $\mathrm{RV}$.

To study the specific contribution of pleural plaques to lung function impairment, the group of subjects with pleural plaques was further analysed according to the absence ('isolated pleural plaques' group) or presence ('pleural plaques and other abnormalities' group) of other CT scan abnormalities. The distribution of parameters in these groups is shown in table 3. In multivariate analysis, for both sexes, after adjusting for age, BMI, CEI to asbestos, smoking status and centre, subjects presenting with isolated pleural plaques (without any other CT scan abnormalities) had a significant decrease in TLC, FVC and $\mathrm{FEV}_{1}$ compared with healthy subjects (no significant relationship being observed with $\mathrm{FEV}_{1} / \mathrm{FVC}$ ratio, $\mathrm{FEF}_{25-75}$ and $\mathrm{RV}$ ), whereas pleural plaques associated with other pulmonary abnormalities (except interstitial abnormalities) were associated with a significant decrease in FVC, $\mathrm{FEV}_{1}, \mathrm{FEV}_{1} / \mathrm{FVC}$ ratio, $\mathrm{FEF}_{25-75}$, RV and TLC. The presence of diffuse pleural thickening was also associated with a significant decrease in all PFT parameters compared with healthy subjects.

As shown in table 4, a significant decrease was observed in TLC and FVC which was linked to the extent of pleural plaques in subjects presenting with isolated pleural plaques. Figure 2 illustrates this trend. In contrast, no significant relationship was observed between maximum pleural plaque thickness and PFT parameters analysed.

\section{DISCUSSION}

Our results confirm a relationship between isolated parietal and/ or diaphragmatic pleural plaques and changes in respiratory function in the form of a trend towards a restrictive pattern as 
Table 3 Demographic data, asbestos exposure and multivariate analysis of lung functional parameters according to the presence of pleural plaques on CT scan

\begin{tabular}{|c|c|c|c|c|c|}
\hline & $\begin{array}{l}\text { Group 1A } \\
\text { Isolated } \\
\text { pleural plaques* }\end{array}$ & $\begin{array}{l}\text { Group 1B } \\
\text { Pleural plaques } \\
\text { and other } \\
\text { abnormalities } \dagger\end{array}$ & $\begin{array}{l}\text { Group } 0 \\
\text { Normal } \\
\text { CT scan } \ddagger\end{array}$ & $\begin{array}{l}\text { p Value } 9 \\
\text { Group 1A/ } \\
\text { Group0 }\end{array}$ & $\begin{array}{l}\text { p Value } \\
\text { Group 1B/ } \\
\text { Group } 0\end{array}$ \\
\hline Number of subjects & 403 & 123 & 1802 & & \\
\hline Gender & & & & 0.0005 & 0.45 \\
\hline Male, n (\%) & $397(98.5)$ & $118(95.9)$ & 1700 (94.3) & & \\
\hline Female, $\mathrm{n}(\%)$ & $6(1.5)$ & $5(4.1)$ & $102(5.7)$ & & \\
\hline Mean (SD) age, years & $64.6(5.4)$ & $65.2(5.8)$ & $62.3(5.3)$ & $<0.0001$ & $<0.0001$ \\
\hline Smoking status & & & & $<0.0001$ & $<0.0001$ \\
\hline Non-smokers, n (\%) & $66(16.4)$ & $15(12.2)$ & $548(30.4)$ & & \\
\hline Ex-smokers, n (\%) & $311(77.2)$ & $92(74.8)$ & $1145(63.5)$ & & \\
\hline Smokers, n (\%) & $26(6.4)$ & $16(13.0)$ & $109(6.0)$ & & \\
\hline Mean (SD) BMI, kg/m² & $27.7(3.8)$ & $26.1(3.8)$ & $27.4(3.7)$ & 0.06 & 0.0004 \\
\hline \multicolumn{3}{|c|}{ Mean (SD) duration of exposure to asbestos (years) } & & 0.02 & 0.33 \\
\hline $1-9, \mathrm{n}(\%)$ & $17(4.2)$ & $6(4.9)$ & $111(6.2)$ & & \\
\hline $10-19, \mathrm{n}(\%)$ & $33(8.2)$ & $7(5.7)$ & $202(11.2)$ & & \\
\hline $20-29, \mathrm{n}(\%)$ & $65(16.1)$ & $24(19.5)$ & $365(20.3)$ & & \\
\hline $30-39, \mathrm{n}(\%)$ & $193(47.9)$ & $58(47.1)$ & $752(41.7)$ & & \\
\hline$\geq 40, \mathrm{n}(\%)$ & $95(23.6)$ & $28(22.8)$ & $372(20.6)$ & & \\
\hline \multicolumn{4}{|c|}{ Cumulative exposure index to asbestos (unit of exposure $\times$ years) } & $<0.0001$ & $<0.0001$ \\
\hline $0-3.4$ & $46(11.4)$ & $20(16.3)$ & $461(25.6)$ & & \\
\hline $3.4-17.2$ & $54(13.4)$ & $11(8.9)$ & $385(21.4)$ & & \\
\hline $17.2-33.1$ & $71(17.6)$ & $14(11.4)$ & $365(20.3)$ & & \\
\hline $33.1-91.9$ & $79(19.6)$ & $31(25.2)$ & $338(18.8)$ & & \\
\hline$\geq 91.9$ & $153(38.0)$ & $47(38.2)$ & $253(14.0)$ & & \\
\hline Mean (SD) & $112.6(128.6)$ & $107.3(118.2)$ & $47.9(83.1)$ & & \\
\hline Median & 39.0 & 42.0 & 20.0 & & \\
\hline \multicolumn{6}{|c|}{ Pulmonary function ( $\%$ predicted $\mathrm{FVC}, \mathrm{FEV}_{1}, \mathrm{FEF}_{25-75}, \mathrm{RV}$ and $\mathrm{TLC}$, absolute ratio for $\left.\mathrm{FEV}_{1} / \mathrm{FVC}\right) \S$} \\
\hline FVC, mean (SD) & $96.6(16.6)$ & $95.9(19.6)$ & $100.4(16.6)$ & $<0.0001$ & 0.0004 \\
\hline FEV1, mean (SD) & $97.9(19.4)$ & $93.5(22.9)$ & $101.9(19.2)$ & 0.0032 & $<0.0001$ \\
\hline $\mathrm{FEV}_{1} / \mathrm{FVC}$, mean (SD) & $79.2(9.0)$ & $75.9(9.8)$ & $80.0(7.9)$ & 0.27 & 0.0025 \\
\hline $\mathrm{FEF}_{25-75}$, mean (SD) & $91.8(36.2)$ & $79.5(37.1)$ & $95.9(35.5)$ & 0.53 & 0.0005 \\
\hline $\mathrm{FEF}_{25}$, mean (SD) & $88.5(53.7)$ & $70.9(43.3)$ & $92.4(60.5)$ & 0.50 & 0.0006 \\
\hline $\mathrm{FEF}_{50}$, mean (SD) & $89.3(34.5)$ & $86.5(70.1)$ & $93.9(34.2)$ & 0.42 & 0.32 \\
\hline $\mathrm{FEF}_{75}$, mean (SD) & $87.5(29.4)$ & $81.1(30.6)$ & $91.8(28.7)$ & 0.20 & 0.009 \\
\hline $\mathrm{RV}$, mean (SD) & $106.5(28.9)$ & $112.6(36.7)$ & $109.1(35.4)$ & 0.8838 & 0.30 \\
\hline TLC, mean (SD) & $98.1(14.2)$ & $99.3(14.0)$ & $101.2(16.0)$ & 0.0494 & 0.20 \\
\hline
\end{tabular}

shown by the observed decrease in TLC, FVC and $\mathrm{FEV}_{1}$. It should nevertheless be noted that these modifications are globally modest since the PFT results are within normal limits. Indeed, the low limited extent of the decrease observed in FVC and TLC raises the question of a real clinical relevance for the subjects affected. The percentage of subjects with TLC below the theoretical value (calculated according to Quanjer et $a l^{23}$ ) was identical in the group presenting with isolated pleural plaques and in the group with a normal CT scan (24.1\%). In contrast, the percentage of subjects presenting with FVC lower than the theoretical value was significantly higher in subjects presenting with isolated pleural plaques than in those with a normal CT scan (9.2\% vs 6.0\%, $\mathrm{p}=0.0222)$.

Furthermore, we observed a significant linear relationship between the extent of pleural plaques on the CT scan and the decrease in pulmonary volume. This is noteworthy in a population in which the degree of pleural damage is, on the whole, limited (table 4). In contrast, no relationship between these benign pleural plaques when isolated and an obstructive pattern was seen in our study. This decrease in pulmonary volumes without impairment of the $\mathrm{FEV}_{1} / \mathrm{FVC}$ ratio has also been observed in other studies, ${ }^{11-16} 1819$ based exclusively on chest radiography. Nevertheless, it is possible that, in these studies, the presence of interstitial abnormalities not visible on chest radiography explained the observed reduction in pulmonary volume. The use of HRCT scanning in our study allowed us to validate the isolated nature of observed parietal and/or diaphragmatic pleural plaques. Furthermore, this examination also enabled us categorically to differentiate them from fibrosis of the visceral pleura (diffuse pleural thickening).

The criteria used to define pleural plaques and visceral pleural thickening in the literature are often heterogeneous and inaccurate, potentially leading to confusion. ${ }^{25}$ However, our large study has confirmed the relationships between diffuse pleural fibrosis and the existence of a functional restrictive impairment reported previously on data based on chest x-rays. ${ }^{4-7}$ In our 
Table 4 Analysis of pulmonary function test parameters according to pleural plaque thickness in subjects with isolated pleural plaques*

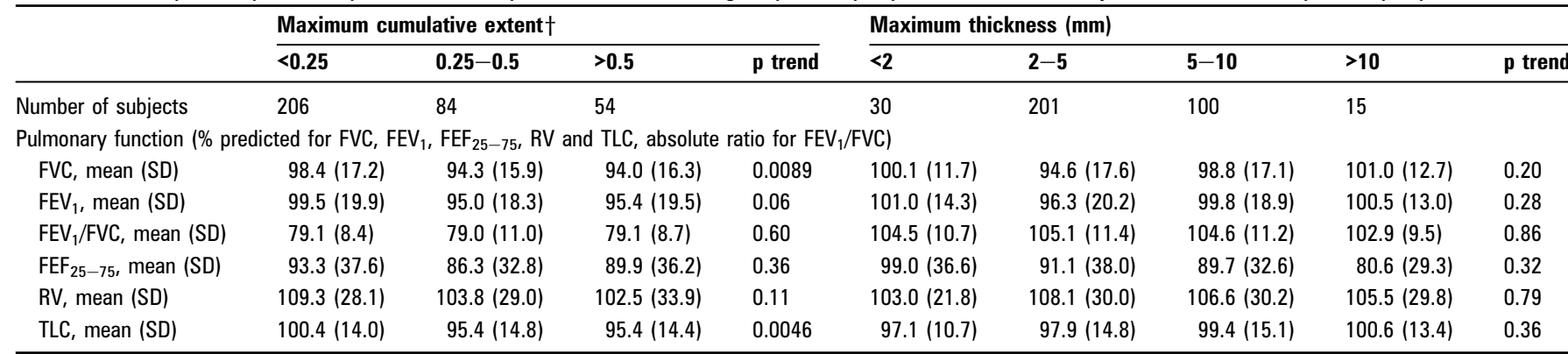

*Multilevel generalised linear model adjusted for age, smoking status, body mass index, cumulative exposure index for asbestos and the centres where pulmonary function tests were conducted.

tThe maximum cumulative extent of pleural plaques corresponded to the sum of their circumference on three levels of reference slice.

$\mathrm{FEF}_{25-75}$, forced expiratory flow at 25-75\% FVC; FEV 1 , forced expiratory volume in $1 \mathrm{~s}$; FVC, forced vital capacity; RV, residual volume; TLC, total lung capacity.

study, pleural plaques associated with other abnormalities (probably not always detected by standard chest radiography) were associated with a significant decrease in FVC, FEV $1, \mathrm{FEV}_{1}$ / FVC ratio and $\mathrm{FEF}_{25-75}$. These results suggest that the previously described association between pleural plaques and airway obstruction $^{26}$ may be due to other abnormalities, mainly emphysema, not detected on chest x-rays.

To our knowledge, only two studies have previously analysed possible associations between pleural plaques on CT scans and respiratory function. ${ }^{9}{ }^{10}$ In the case study conducted in 2001 among 73 subjects exposed to asbestos (CEI ranging from 16.4 to 98.7 fibres/ml $\times$ year) who underwent HRCT, the authors reported no relationship between the extent of diagnosed pleural plaques in $70 \%$ of subjects and lung function impairment. ${ }^{9}$ The second study, which analysed possible associations between pleural plaques on the $\mathrm{CT}$ scan and respiratory function, included only 50 subjects presenting with pleural plaques and/or pleural thickening, 20 of whom had been exposed to asbestos. ${ }^{10}$ The apparent differences between the results of these two studies and our own study are probably associated with the higher statistical power generated by the number of included subjects.

There are some limitations to our study. First, because the study subjects were retired or inactive volunteers, they are not representative of the general population of subjects exposed to asbestos, a number of whom are still professionally active. Another possible selection bias is that subjects who had previously been diagnosed with asbestos exposure-related diseases and/or those already under medical surveillance for severe respiratory insufficiency may not have deemed participation in

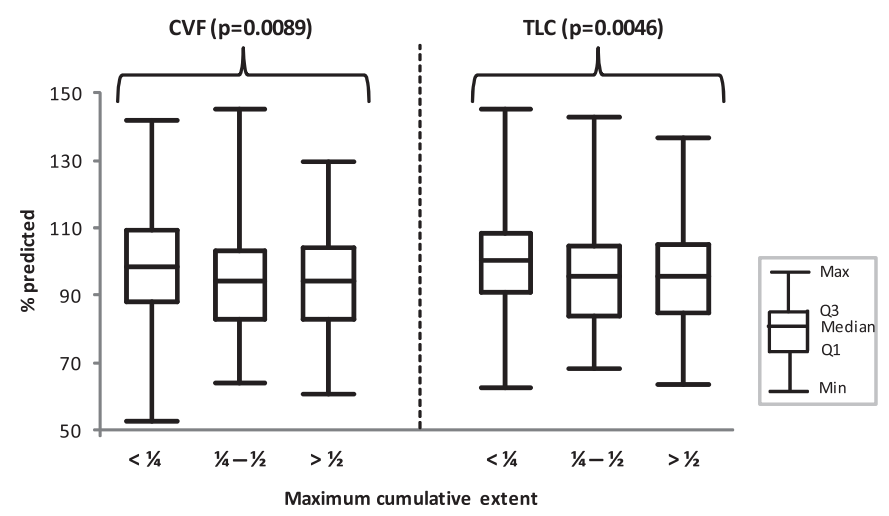

Figure 2 Decrease in total lung capacity (TLC) and forced vital capacity (FVC) according to the extent of plaques. max, maximum; 03, 3rd quartile (75\%); 01, 1st quartile (25\%); min, minimum. a screening campaign to be useful, thus explaining the good results obtained on PFTs. Moreover, a healthy worker effect can be suspected among subjects who have had extensive exposure which would also account for the good PFT results in the study population. Nevertheless, we assume that this patient selection does not alter the nature of our results, particularly in patients presenting with isolated pleural plaques generally considered as asymptomatic. Furthermore, this does not explain the relationship between the extent of pleural plaques and the changes in PFTs observed in our study.

We have chosen a simplified approach for the assessment of the extent of pleural plaques based only on three reference levels for CT scan slices. This was justified to be compatible with the organisation of the independent reading of more than 5000 CT scans in the whole study (data not shown). As a result, we did not perform any spatial reconstruction or more sophisticated surface calculations, unlike some other authors. ${ }^{9} 18$

We excluded 57 subjects with clearly aberrant PFT results from the analysis and we adjusted for the centre in which PFTs were performed in the multilevel unconditional logistic model to take into account the centre variability. We also performed a posteriori quality control for PFTs on a randomly selected sample. ${ }^{20}$ Based on the pattern of the flow-volume curve and the similarity between FVC and slow VC, 95\% of PFTs were considered perfect to satisfactory. We therefore consider that the PFTs can be considered valid. As expected, smokers and exsmokers had significantly more obstructive impairment than non-smokers (data not shown), and this reinforces the credibility of our PFT data.

The strengths of our study are the large number of subjects $(n=2743)$, the individual estimation of cumulative occupational exposure to asbestos and the accurate determination of asbestosrelated pleuropulmonary abnormalities by a CT scan of the chest and the standardised and independent double (in some cases triple) reading by thoracic radiology experts.

\section{CONCLUSION}

Our results show a relationship between isolated pleural plaques diagnosed on the CT scan and lung function impairment in the form of a trend towards a restrictive pattern, significantly increasing in proportion to the extent of pleural plaques, although the observed decrease in FVC and TLC is unlikely to be of real clinical relevance for the majority of subjects in this series. We also confirm the association between diffuse pleural thickening and a restrictive pattern.

Acknowledgements The authors would like to thank the other members of the asbestos post-exposure programme for their contribution to this survey: E Abboud, 
Y Badachi, J Baron, C Beigelman-Aubry, J Benichou, A Bergeret, A Caillet, P Catilina, S Chamming's, G Christ de Blasi, G Ferretti, E Guichard, A Jankowski, V Latrabe, N Le Stang, MF Marquignon, B Millet, M Montaudon, L Mouchot, M Pinet, A Porte, P Reungoat, R Ribero, M Savès, A Sobaszek, A Stoufflet, FX Thomas, L Thorel and the practitioners of security insurance (Aquitaine, Upper Normandy, Lower Normandy and Rhône-Alpes).

Funding This study was supported by grants from the French National Health Insurance (Occupational Risk Prevention Department), the French Ministry of Labor and Social Relations and the ANSES (07 CRD 51 and EST 2006/1/43)

Patient consent Obtained.

Ethics approval Ethics approval was granted by the Cochin Hospital ethics committee in Paris.

Provenance and peer review Not commissioned; externally peer reviewed.

\section{REFERENCES}

1. American Thoracic Society. Diagnosis and initial management of nonmalignant diseases related to asbestos. Am J Respir Crit Care Med 2004;170:691-715.

2. Miller A. Pulmonary function in asbestosis and asbestos-related pleural disease. Environ Res 1993:61:1-8

3. Schwartz DA, Davis CS, Merchant JA, et al. Longitudinal changes in lung function among asbestos-exposed workers. Am J Respir Crit Care Med 1994;150:1243-9.

4. Bourbeau J, Ernst P, Chrome J, et al. The relationship between respiratory impairment and asbestos-related pleural abnormality in an active work force. Am Rev Respir Dis 1990:142:837-42.

5. McGavin CR, Sheers G. Diffuse pleural thickening in asbestos workers: disability and lung function abnormalities. Thorax 1984;39:604-7.

6. Yates DH, Browne K, Stidolph PN, et al. Asbestos-related bilateral diffuse pleura thickening: natural history of radiographic and lung function abnormalities. $A m \mathrm{~J}$ Respir Crit Care Med 1996;153:301-6.

7. Schwartz DA, Galvin JR, Yagla SJ, et al. Restrictive lung function and asbestosinduced pleural fibrosis. A quantitative approach. J Clin Invest 1993;91:2685-92.

8. Peacock C, Espley SJ, Hansell DM. Asbestos-related benign pleural disease. Clin Radiol 2000:55:422-32.

9. Van Cleemput J, De Raeve H, Verschakelen JA, et al. Surface of localized pleural plaques quantitated by computed tomography scanning. No relation with cumulative exposure and no effect on lung function. Am J Respir Crit Care Med 2001:163:705-10

10. Copley SJ, Wells AU, Rubens MB, et al. Functional consequences of pleural disease evaluated with chest radiography and CT. Radiology 2001;220:237-45.
11. Baker EL, Dagg T, Greene RE. Respiratory illness in the construction trades. I. The significance of asbestos-associated pleural disease among sheet metal workers. J Occup Med 1985;27:483-9.

12. Jarvholm B, Sanden A. Pleural plaques and respiratory function. Am J Ind Med 1986;10:419-26

13. Jarvholm B, Larsson S. Do pleural plaques produce symptoms? A brief report. J Occup Med 1988;30:345-7.

14. Fridricksson HV, Hedenstrom $\mathrm{H}$, Hillerdal $\mathrm{G}$, et al. Increased lung stiffness in persons with pleural plaques. Eur J Respir Dis 1981:62:412-24.

15. Rosenstock L, Barhart $\mathrm{S}$, Heyer NJ, et al. The relation among pulmonary funtion chest roentgenographic abnormalities, and smoking status in an asbestos-exposed cohort. Am Rev Respir Dis 1988;136:272-7.

16. Oliver LC, Eisen EA, Greeene RE, et al. Asbestos-related pleural plaques and lung function. Am J Ind Med 1988:14:649-56.

17. Kilburn KH, Warshaw R. Pulmonary functional impairment associated with pleural asbestos disease. Chest 1990;98:965-72.

18. Schwartz DA, Fourtes LJ, Galvin JR, et al. Asbestos-induced pleural fibrosis and impaired lung function. Am Rev Respir Dis 1990;141:321-6.

19. Lilis R, Miller A, Godbold J, et al. Pulmonary function and pleural fibrosis: quantitative relationship with an integrative index of pleural abnormalities. Am J Ind Med 1991;20:145-61.

20. Paris C, Thierry S, Brochard P, et al; the APEXS members. Pleural plaques and asbestosis: dose and time response relationships based on HRCT data. Eur Respir $J$ 2009; $34: 72-9$

21. Ameille J, Letourneux $\mathrm{M}$, Paris $\mathrm{C}$, et al. Does asbestos exposure cause airway obstruction, in the absence of confirmed asbestosis? Am J Respir Crit Care Med 2010;182:526-30.

22. Anon. Conférence de consensus pour l'élaboration d'une stratégie de surveillance médicale clinique des personnes exposées à l'amiante. Rev Mal Respir 1999;16:1190-388.

23. Quanjer PH, Tammeling GJ, Cotes JE, et al. Lung volumes and forced ventilatory flows. Report Working Party Satndardization of Lung Function Tests, European Community for Steel and Coal. Official Statement of the European Respiratory Society. Eur Respir J Supp/ 1993:16:5-40.

24. Gevenois PA, De Maertelaer V, Madani A, et al. Asbestosis, pleural plaques and diffuse pleural thickening: three distinct benign responses to asbestos exposure. Eur Respir J 1998;11:1021-7.

25. Ameille J, Matrat M, Paris C, et al. Asbestos-related pleural diseases: dimensiona criteria are not appropriate to differentiate diffuse pleural thickening from pleural plaques. Am J Ind Med 2004;45:289-96.

26. Kilburn KH, Warshaw RH. Abnormal lung function associated with asbestos disease of the pleura, the lung, and both: a comparative analysis. Thorax 1991;46:33-8

\section{The role of leukotriene receptor antagonists in asthma}

\section{This study assessed the effectiveness of a leukotriene receptor antagonist (LTRA) in two} pragmatic randomised controlled trials over a 2-year period in primary care practices across the UK. The first trial compared LTRAs with inhaled glucocorticoids as the first-line treatment in asthma. The second trial compared the addition of LTRAs versus the addition of long-acting $\beta_{2}$-agonists in patients already using inhaled glucocorticoids with asthma.

All treatments led to significant improvements in the primary outcome measure: the mini Asthma Quality of Life Questionnaire. At 2 months, the LTRA was found to be equivalent in both studies. At 2 years, there was a trend towards equivalence between treatment groups although scores fell outside of their pretest definition of equivalence. Secondary outcome measures including asthma control questionnaire scores and frequency of exacerbations were not significantly different between treatment groups

The results suggest a trend towards equivalence when LTRAs are compared with standard therapy both as first-line and as add-on therapy when used long term. However, the trial is weakened by the proportion of treatment changes required, which was consistently higher for patients using LTRAs in both studies.

- Price D, Musgrave SD, Shepstone L, et al. Leukotriene antagonists as first-line or add-on asthma-controller therapy. $N$ Eng/ J Med 2011:364:1695-707.

\section{Andrew Low}

Correspondence to Dr Andrew Low, ST4, Respiratory Medicine, University Hospitals Bristol, Marlborough Street, Bristol BS1 3NU, UK; andytlow@hotmail.com 